\title{
TEM and Mechanical Characterization in Al-C Composite
}

I. Estrada-Guel ${ }^{1}$, A.Santos-Beltrán ${ }^{1}$, J. Morales-Hernández ${ }^{2}$, F. Paraguay-Delgado ${ }^{1}$, C. CarreñoGallardo, J.I Barajas-Villaruel ${ }^{3}$ and R. Martínez-Sánchez ${ }^{1 *}$.

${ }^{1}$ Centro de Investigación en Materiales Avanzados (CIMAV), Miguel de Cervantes No.120, C.P. 31109, Chihuahua, Chih., México.

2 Transmisiones y Equipos Mecánicos, S.A. de C. V. (TREMEC), 5 de Febrero No. 2115, C.P. 76120, Querétaro, Qro., México

${ }^{3}$ Universidad Autónoma de San Luis Potosí, Alvaro Obregón No. 64, C.P. 78000, San Luis Potosí, S.L.P., México.

Aluminum-graphite Al-C novel composites have been produced using the Mechanical Alloying process (MA). The mechanics properties of the obtained composites have been evaluated. $\sigma_{\mathbf{y}}$ values reached in the composites are considerably higher than that reported for pure aluminum. There is a direct relationship between $\sigma_{\mathbf{y}}$ and final metal-coated graphite content in the composite. $\sigma_{\mathbf{y}}$ values increase as the nominal $\mathrm{C}$ content increases as well. The most important hardening element was the graphite. The simplicity of the process it is major attribute. Al (99.9\% pure, -200 mesh in size) and previously metal-coated graphite (-300 mesh) powders were used as raw materials. Different compositions of metal-coated graphite were studied, C-15\%Me, C-25\%Me, C-35\%Me and C$45 \% \mathrm{Me}$. Three mixtures of Al-based metal-matrix-composites (MMC's) were obtained, Al- $0.5 \% \mathrm{wt}$ metal-coated graphite (MCG), Al-1.0\%wt MCG and Al-2.0\%wt MCG. Each mixture was mechanically milled in a high energy shaker mill (SPEX-8000) during $1 \mathrm{~h}$. Argon was used as milling atmosphere. Devices and milling media used were made from hardened steel. The milling ball to powder weight ratio was 5 to 1 .

Table I shows, nomenclature, nominal composition and different compositions of material employed in the present work. It also includes theoretical density $(\rho)$, maximum and minimum $\sigma_{\mathbf{y}}$ values reported for sintered samples during the compression tests. $\rho$ values of all compositions studied in the present work are very close to that reported for pure aluminum $\left(\sim 2.7 \mathrm{~g} / \mathrm{cm}^{3}\right)$. From this table it is observed that $\sigma_{\mathbf{y}}$ has a direct relationship with nominal concentration of graphite in the composite. Different case was the effect of the copper; in this case, there is no relationship with final mechanical properties. Obtained data of $\sigma_{\mathbf{y}}$ are higher than those of several as-cast Al-alloys reported in literature, and very close to that heat treated (T6) Al-alloys. Figure 1 shows a direct relationship between $\sigma_{\mathbf{y}}$ and final $\mathrm{MCG}$ content in the composite. At low content (concentration) of MCG there is less data dispersion.

During compression testing it was observed that the composite corresponding to the composition Al$2.0 \%$ MCG showed less ductility without exhibiting substantial increase in $\sigma_{\mathbf{y}}$. From the Table I and Figure 1, it is observed that for the composite Al-0.5 MCG samples with less Cu content showed higher $\sigma_{\mathrm{y}}$, confirming that the main hardening element was the dispersed graphite into $\mathrm{Al}$ matrix. Figure 2 shows a representative TEM micrograph of a reinforced particle of composite Al-1.0\% MCG in the as-sintered condition. The small size of particle is evident. As it has been reported above, graphite particles are coated by a $\mathrm{Cu}$ film. This is more evident in the inset square. The thickness of coating it is smaller to $10 \mathrm{~nm}$. TEM studies are currently being carried out on the $\mathrm{C}-\mathrm{Cu}$ film interphase and on Al-film interphase. 
Table I.- General results obtained in the Al-based composites.

\begin{tabular}{|c|c|c|c|c|c|c|}
\hline \multirow{2}{*}{ Composite } & \multirow{2}{*}{$\begin{array}{c}\text { Composition } \\
\text { MCG }\end{array}$} & \multicolumn{2}{|c|}{$\begin{array}{c}\text { Nominal } \\
\text { Composition (wt \%) }\end{array}$} & \multirow{2}{*}{$\begin{array}{l}\sigma_{y} \min \\
(\mathrm{MPa})\end{array}$} & \multirow{2}{*}{$\begin{array}{l}\sigma_{y \max } \\
(\mathbf{M P a})\end{array}$} & \multirow{2}{*}{$\begin{array}{c}\rho_{\text {(theoretical) }}^{\left(\mathrm{g} / \mathrm{cm}^{3}\right)} \\
\end{array}$} \\
\hline & & $\mathbf{C u}$ & $\mathrm{C}$ & & & \\
\hline \multirow{4}{*}{ Al-0.5 MCG } & $\mathrm{C}-45 \%$ wt $\mathrm{Cu}$ & 0.225 & 0.275 & 170.9 & 173.3 & 2.7129 \\
\hline & $\mathrm{C}-35 \%$ wt $\mathrm{Cu}$ & 0.175 & 0.325 & 176.0 & 174.8 & 2.7095 \\
\hline & $\mathrm{C}-25 \%$ wt $\mathrm{Cu}$ & 0.125 & 0.375 & 180.4 & 182.0 & 2.7062 \\
\hline & $\mathrm{C}-15 \%$ wt $\mathrm{Cu}$ & 0.075 & 0.425 & 183.6 & 184.8 & 2.7028 \\
\hline \multirow{4}{*}{ Al-1.0 MCG } & $\mathrm{C}-45 \%$ wt $\mathrm{Cu}$ & 0.450 & 0.550 & 208.1 & 212.9 & 2.7258 \\
\hline & $\mathrm{C}-35 \%$ wt $\mathrm{Cu}$ & 0.350 & 0.650 & 228.4 & 229.6 & 2.7191 \\
\hline & $\mathrm{C}-25 \%$ wt $\mathrm{Cu}$ & 0.250 & 0.750 & 251.8 & 281.9 & 2.7124 \\
\hline & $\mathrm{C}-15 \%$ wt $\mathrm{Cu}$ & 0.150 & 0.850 & 244.2 & 250.6 & 2.7057 \\
\hline \multirow{4}{*}{ Al-2.0 MCG } & $\mathrm{C}-45 \%$ wt $\mathrm{Cu}$ & 0.900 & 1.100 & 252.2 & 268.1 & 2.7515 \\
\hline & $\mathrm{C}-35 \%$ wt $\mathrm{Cu}$ & 0.700 & 1.300 & 264.4 & 268.0 & 2.7381 \\
\hline & $\mathrm{C}-25 \%$ wt $\mathrm{Cu}$ & 0.500 & 1.500 & 309.3 & 312.8 & 2.7247 \\
\hline & $\mathrm{C}-15 \%$ wt $\mathrm{Cu}$ & 0.300 & 1.700 & 299.7 & 310.4 & 2.7113 \\
\hline
\end{tabular}

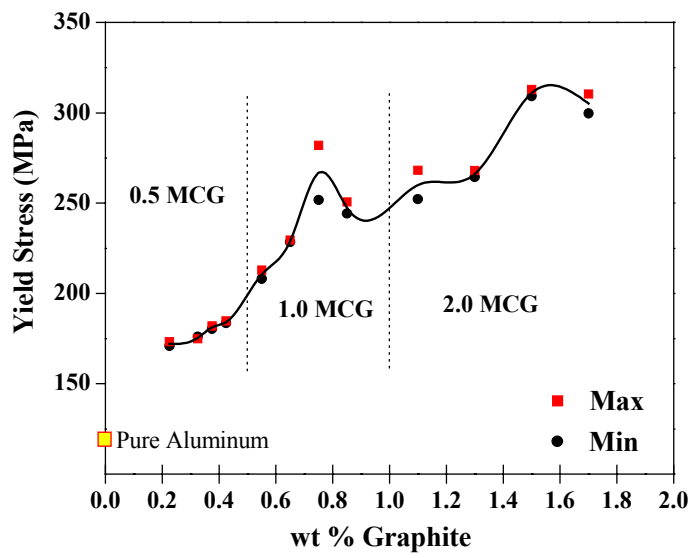

Figure 1.- Yield Stress as a function of nominal \% graphite in composites. Dotted lines shows the regions corresponding to different composite compositions.

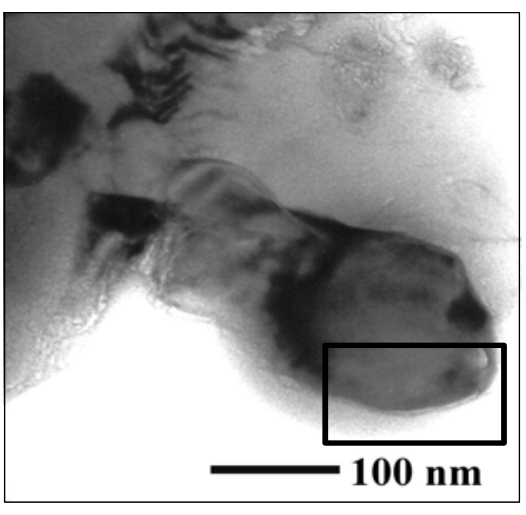

Figure 2.- TEM micrograph showing a graphite particle embedded into Al matrix. Inset square shows the evidence of $\mathrm{Cu}$ cover. 